\section{Questión}

Periodismo / Comunicación ISSN 1669-6581
- Av. $44 \mathrm{~N}^{\circ} 676,1^{\circ}$ piso

CP 1900 - La Plata - Argentina

(i) www.perio.unlp.edu.ar/question

El aula sin muros: lo que nos está enseñando la cuarentena

Francisco Albarello

DOI: https://doi.org/10.24215/16696581e307

\title{
El aula sin muros: lo que nos está enseñando la cuarentena
}

\section{The classroom without walls: what quarantine is teaching us}

Francisco Albarello / falbarello@austral.edu.ar Doctor en Comunicación Social por la Universidad Austral. Licenciado en Comunicación Social con orientación en Periodismo por la Universidad Nacional de la Plata. Postgrado en Educación a distancia a través de redes digitales y recursos de Internet por la Universidad de Murcia (España). Investigador categoría 3 del Programa de Incentivos (Universidad Nacional de San Martín, Res. 5423/18)

Pasado más de un mes del aislamiento social preventivo decretado por el gobierno argentino con motivo de la pandemia COVID 19, resulta difícil realizar algunas reflexiones sin caer en cosas ya dichas en la multiplicidad de redes sociales, sitios web y medios informativos que se han hecho eco del fenómeno. Como no podía ser de otra manera, un tema acapara la agenda mediática y no faltan panelistas, profetas y pseudo pensadores que nos dicen a los docentes cómo debemos usar las "nuevas" tecnologías para la enseñanza en tiempos de cuarentena. A esto se ha sumado la avalancha de solidaridad de pedagogos, tecnólogos educativos, especialistas en tecnología y didáctica y docentes curiosos que vienen incorporando las tecnologías en su forma de dar clases desde hace tiempo. Con ellos compartimos la sensación de que esto que está sucediendo, forzado por las circunstancias que impone el aislamiento social obligatorio, debería haber sucedido hace mucho tiempo atrás. Lo que parecía una situación de emergencia para salir del apuro se ha transformado en una oportunidad para repensar el modo de dar clase, en todos los niveles educativos. No recuerdo una situación similar desde que el Programa Conectar Igualdad distribuyera netbooks a los estudiantes de las escuelas secundarias públicas de todo el país. Si bien la situación es muy distinta a la de 
aquel entonces, introdujo la necesidad de plantearse cómo enseñar y aprender cuando está la posibilidad de usar computadoras personales a nivel masivo. Claro, Conectar Igualdad quedó atrás -aunque antes de la pandemia el gobierno nacional había anunciado su relanzamientopero ahora el desafío reaparece redoblado: forzado por las circunstancias, con incentivos cruzados que no obedecen todos ellos a las necesidades de mejorar la enseñanza, no queda otra alternativa que utilizar los dispositivos digitales para dar clase.

Ahora bien, ¿cómo ese está dando esa inclusión masiva de tecnología en la enseñanza? Si es difícil hacer reflexiones sobre la marcha de la cuarentena social en la multiplicidad de aspectos que trae aparejados, es imposible evaluar la diversidad de prácticas que están teniendo lugar en las escuelas y universidades de todo el país. Hay un ruido, por momentos ensordecedor, provocado por la multiplicación de plataformas de streaming -con la tan cuestionada Zoom a la cabeza, que de un día para el otro se transformó en la segunda aplicación utilizada a nivel mundial-, la proliferación de propuestas de enseñanza que pululan por las redes en tutoriales de Youtube, webinars de especialistas que nos invitan a pensar cómo enseñar hoy con las aplicaciones más populares (WhatsApp, Instagram, etc.), y las opiniones de quienes ven en este contexto un rostro mas del capitalismo avanzado que ha transformado la educación en un commodity y a los sujetos en objetos víctimas de la sociedad de la vigilanciai, gracias a la posibilidad de control social que brinda el software, en manos de multinacionales a las que no le interesa tanto la enseñanza como la acumulación de información personal de los usuarios.

Más allá de estos planteos, que no hacen justicia a la polifónica conversación que está teniendo lugar en estos momentos en las redes sobre qué es enseñar y qué es aprender hoy, voy a proponer aquí algunas reflexiones alrededor del concepto de interfaz. Siguiendo a Carlos Scolari (2018), al sistema educativo se lo puede pensar como una interfaz en crisis. Hay un contrato de lectura entre los alumnos y los docentes que se juega en el espacio interactivo de la interfaz, que es el aula. Como sabemos todos los que venimos trabajando en el ámbito de la enseñanza y la tecnología, ese espacio de interacción necesitaba desde hace tiempo una actualización, para responder a las demandas de unas audiencias cada vez más heterogéneas y moldeadas por formas de consumo y relación con los contenidos muy diversas a lo que ofrecía el aula. Si la enseñanza estaba centrada en el libro impreso y en el aula frontal como dispositivo, y en la explicación lineal como mecanismo central para generar atención, con un mensaje enlatado para ser consumido "de uno a muchos"; en el contexto actual, donde el aula 
es la computadora o el celular conectados en el hogar, esta interfaz ha terminado de estallar. Si el acto educativo estaba pensado como un grupo de cuerpos encerrados unas cuantas horas entre cuatro paredes, con un docente al frente explicando un tema, hegemonizando la "economía de la atención" (Simon, 1971) a través de una pizarra y sostenido en el canal monomediático de su voz; hoy el escenario ha cambiado dramáticamente. El acto educativo tiene lugar a través de pantallas que conviven con otros usos y usuarios, en un lugar complejo que es el hogar, en el que convive el home schooling de los chicos con el home working de los padres. Como nunca antes, el hogar es escenario de disputas por escritorios, pantallas, Wi fi, impresoras y escáners (en el mejor de los casos), para cumplir con las tareas y responder a las demandas que se han multiplicado exponencialmente. Pareciera que ante la falta del contacto físico, los docentes sienten la obligación de enviar tareas en forma continua bajo el supuesto de que a tanta cantidad de horas en el aula le corresponden tantas hora frente a una computadora, soslayando muchas veces las complejidades que tiene el hogar, que hoy se ha convertido en una interfaz de aprendizaje. Si en el aula el chico o la chica estaba solamente para la tarea escolar, en el hogar está para eso y mucho más. Se demanda la misma atención que se le pide en la clase, y la ausencia física conlleva ciertos condicionantes afectivos que no se resuelven a través de mensajes de texto o videos en una plataforma.

Una característica fundamental de las interfaces es que se vuelven transparentes con el uso: "la mejor interfaz es la que no se siente", sostienen los diseñadores de interfaces. En "El ordenador invisible" (2000), Begoña Gros Salvat sostenía que hasta tanto las computadoras no estuvieran integradas a la vida escolar al punto de pasar desapercibidas, no íbamos a poder pensar en pedagogía. En otras palabras, cuando aparece un nuevo medio o tecnología, toda nuestra atención se la lleva el manejo del dispositivo, la necesidad de controlarlo, y hasta tanto eso no sucede no podemos pensar qué hacer con ese dispositivo. No tenemos la libertad y la autonomía para tomar decisiones pedagógicas hasta tanto no sintamos que manejamos esa tecnología para hacerle hacer lo que queremos.

En cambio, el aula tradicional es una interfaz que se ha vuelto invisible hace mucho tiempo atrás. Nadie se cuestiona cómo usar el pizarrón y los libros, tampoco ponemos en cuestión la disposición lineal de los bancos mirando al frente. Asimismo, las interfaces no son neutrales ni inofensivas: su construcción nos condiciona hacia usos específicos, su configuración habilita algunas cosas e impide otras. Ahora bien, ¿cómo trasladar ese razonamiento al contexto actual 
de confinamiento en el hogar? Podemos decir que ahora la interfaz de aprendizaje es el hogar, y que estamos en pleno proceso de invisibilización de esa interfaz. Como ha pasado a lo largo de la historia de los medios y tecnologías, le hacemos hacer al nuevo medio las cosas que hacíamos con el medio anterior. Ya lo decían McLuhan y Fiore en 1967 en El medio es el masaje: "miramos el presente en un espejo retrovisor. Avanzamos hacia el futuro yendo hacia atrás" (McLuhan y Fiore, 2015, p. 41). La tendencia a realizar lo mismo con las nuevas herramientas ha dado lugar a una proliferación de tareas sin el debido contexto: clases por Zoom u otras plataformas de videoconferencia que buscan sustituir las clases presenciales y el uso de material enlatado para recrear un vínculo artificial de cercanía con los alumnos. Todo eso está condenado al fracaso si no reconocemos la naturaleza del nuevo entorno y sus demandas.

La problemática relación entre la escuela y el hogar no es algo nuevo. Los que han estudiado la relación entre la enseñanza y los medios y tecnologías, han observado tempranamente un divorcio entre el mundo real de los chicos y lo que les ofrecía la escuela. Ya en la segunda década del siglo XX, el reconocido pedagogo francés Celestin Freinet había advertido esa separación, lo que le llevó a crear "El libro de la vida" un antecedente del periodismo escolar en el cual los chicos traían al mundo de la escuela lo que sucedía en su casa, en su barrio (Huergo, 2001). De allí que la relación entre el alfabetismo mediático y el alfabetismo transmedia (Scolari, 2016) viene a zanjar esa distancia al proponer un diálogo entre la cultura de las aulas y la cultura de los estudiantes, atravesados en su subjetividad por el cambio tecnológico. En los años ochenta y noventa por ejemplo, la preocupación era cuántas horas pasaban los chicos al frente de un televisor (Ferrés, 1994; Pérez Tornero, 1994), y esto ha llevado, adicionalmente, al menosprecio y a subestimación del lenguaje audiovisual, ya que la enseñanza -al estar centrada en el libro como dispositivo hegemónico- consideró a estos medios como géneros menores, y en muchos casos los culpables de la supuesta decadencia cultural. ¿Qué es lo que sucede ahora en contexto de cuarentena? Estamos ante una relación inédita entre el aula y el hogar. Como nunca antes, el vínculo entre estas dos interfaces se ha estrechado: el hogar se ha transformado en un aula portátil, reducida a una pantalla y dependiente de una conexión a Internet. Las tareas han trascendido como nunca las hojas de carpetas o cuadernos: se han desmaterializado mediantes escaneos y envíos a plataformas, programas de mensajería o correo electrónico. Las explicaciones están en las pantallas: ya sea 
en tutoriales de Youtube o en plataformas sincrónicas con un profesor que a su vez deja ver detrás suyo que él también está en su hogar, atravesado por estas interfaces que se superponen. El silencio y el ruido del aula se han trasformado en un coro de micrófonos que nos traen las voces y sonidos de cada hogar, los perros, los hermanitos o hermanitas, los teclados que resuenan frenéticamente porque como nunca se están usando para producir tareas para enviar.

En 1981, Marshall McLuhan y Edmund Carpenter publicaron el libro El aula sin muros, donde planteaban precisamente que la mayor parte de la enseñanza tenía lugar fuera del aula en virtud del contacto de los alumnos con los medios de comunicación. Pasaron ya 40 años de aquel ensayo. Hasta el 20 de marzo pasado las aulas seguían como siempre, en muchos casos cerradas a la novedad de los medios. Como sostiene Mariana Maggio (2012), la tecnología interpela epistemológicamente a los docentes en la disciplina que enseñan, y cognitivamente a las subjetividades de nuestros alumnos, atravesados por estas tecnologías. También nos interpelan a nosotros en nuestras propias subjetividades, en nuestra manera de relacionarnos, de acceder a la información y de pensar. Para tomar dimensión de esto podemos preguntarnos: ¿qué sería de esta cuarentena sin Internet? En la repuesta está contenida esa interpelación de la que hablamos.

Entonces, estamos ante una oportunidad enorme: más allá de pensar qué herramientas podemos usar para dar clases a través de Internet, o dónde encontrar un tutorial que nos enseña a manejarlas, debemos partir de la convicción de que estamos ante una nueva relación entre el mundo de la vida de los alumnos, confinados en sus hogares, y el mundo de la escuela. Ese mundo de la escuela o la universidad, que está conformada por docentes que también están confinados en sus hogares, ya no es el mismo: las condiciones que nos toca vivir han transformado las maneras de generar y circular el conocimiento. Debemos dejar las viejas vestiduras de las formas anteriores y animarnos a ensayar con nuevos envases, a probar y equivocarnos. Usemos parte de nuestra energía cognitiva, totalmente volcada a aprender a utilizar las tecnologías que nos han impuesto las circunstancia, a repensar el modo de dar clase, a recrear una "didáctica en vivo" (Maggio, 2018), que no se da en un aula presencial cara a cara, sino que sucede a través de pantallas. El acto educativo puede tener lugar, asumiendo rasgos diferentes, desafiando nuestros esquemas y alterando la zona de confort a la que estábamos acostumbrados. 
El desafío es hoy, no lo podemos dejar pasar. La cuarentena terminará, pero las clases ya no pueden ser las mismas.

Referencias

Ferrés, J. (1994). Televisión y educación, Barcelona: Paidós.

Gros Salvat, B. (2000). El ordenador invisible: hacia la apropiación del ordenador en la enseñanza, Barcelona: Gedisa.

Huergo, J. (Ed), (2001). Comunicación/Educación. Ámbitos, Prácticas y Perspectivas, La Plata: Ediciones de Periodismo y Comunicación.

Maggio, M. (2012). Enriquecer la enseñanza: los ambientes con alta disposición tecnológica como oportunidad, Buenos Aires: Paidós.

Maggio, M. (2018). Reinventar la clase en la universidad. Buenos Aires: Paidós.

McLuhan, M. y Fiore, Q. (2015). El Medio es el Masaje: Un inventario de efectos, Buenos Aires: La Marca Editora.

Pérez Tornero, J. M. (1994). El desafío educativo de la televisión. Para comprender y usar el medio, Barcelona: Paidós.

Scolari, C. (2018). Las leyes de la interfaz: diseño, ecología, evolución, tecnología, Barcelona: Gedisa.

Scolari C. (2016). Alfabetismo transmedia: estrategias de aprendizaje informal y competencias mediáticas en la nueva ecología de la comunicación. Telos (193): 13-23. Disponible en: https://telos.fundaciontelefonica.com/archivo/numero103/estrategias-de-aprendizaje-informal-ycompetencias-mediaticas-en-la-nueva-ecologia-de-la-comunicacion/ (recuperado el 30 de abril de 2020)

Simon, H. (1971). "Designing Organizations for an Information-rich World", en M. Greenberger (Ed.), Computers, communications, and the public interest. Baltimore, MD: The Johns Hopkins Press.

Notas 
' En este contexto es interesante destacar que, en Vigilar y castigar, Michel Foucault (1975), habla del panóptico, un dispositivo de vigilancia creado a fines del siglo XVIII que tuvo lugar en las ciudades donde precisamente se declaraba una peste. 